\title{
A PROTEÇÃO DA IMAGEM, DA PRIVACIDADE E DA INTIMIDADE EM FACE DA POSSIBILIDADE DE SUA VIOLAÇÃO E EXPOSIÇÃO PELOS MEIOS DE COMUNICAÇÃO E NAS REDES SOCIAIS
}

\author{
Horácio Monteschio ${ }^{1}$ \\ Valeria Juliana Tortato Monteschio ${ }^{2}$
}

\section{Resumo}

Uma das maiores preocupações na atualidade reside na possibilidade de exposição de dados e conversas privadas. A proteção prevista no art. $5^{\circ}$, incisos V e X da Constituição Federal de 1988 poderá assumir contornos de desprestigio caso esses direitos não venham a ser efetivamente protegidos. A prática hodierna demonstra que a facilidade com que os meios de comunicação obtém informações íntimas e privadas de pessoas. Assim, aquilo que deveria estar salvaguardado sob o manto da privacidade, da individualidade, ou mesmo de interesse dos seus titulares podem se tornar públicos, quebrando a regra de ouro da inviolabilidade de intimidade

Palavras-chave: intimidade, vida privada, divulgação de conversas obtidas por meios ilícitos, sigilo da fonte.

\section{PROTECTION OF IMAGE, PRIVACY AND INTIMACY AGAINST THE POSSIBILITY OF ITS BREACH AND EXPOSURE BY THE MEDIA AND SOCIAL NETWORKS}

\begin{abstract}
One of the biggest concerns today is the possibility of data exposure and private conversations. The protection provided for in art. 5, items V and X of the Federal Constitution of 1988 may assume contours of discredit if these rights are not effectively protected. Today's practice demonstrates that the ease with which the media obtains intimate and private information from people. Thus, what should be safeguarded under the cloak of privacy, individuality, or even in the interests of its holders can become public, breaking the golden rule of inviolability of intimacy and private life.
\end{abstract}

Keywords: intimacy, private life, dissemination of conversations obtained by illicit means, source confidentiality.

\section{INTRODUÇÃO}

\footnotetext{
${ }^{1}$ Pós doutorando pelo UNICURITIBA e pela UNIVERSIDADE DE COIMBRA, doutor em direito pela FADISP, mestre em direito pelo UNICESUMAR. professor do UNICURITIBA

${ }^{2}$ Graduada em direito pela universidade Estadual de Maringá. Mestre em Educação.
} 
Os direitos de personalidade, no Brasil, foram efetivamente reconhecidos com a promulgação da Constituição Federal de 5 de outubro de 1988, de forma a consagrar a cláusula genérica da dignidade da pessoa humana em seu art. $1^{\circ}$, inc. III. Posteriormente, com a entrada em vigor do Código Civil brasileiro, Lei $\mathrm{n}^{\circ}$ 10.406/02, os direitos da personalidade receberam tratamento que não havia sido concedido no Código de 1916.

A justificativa para ausência no Código Civil de 1916, entre os seus comandos normativos, reside no fato de quando da sua concepção, no sistema legal pátrio, preponderava à proteção do patrimônio privado, em razão da forte influência do liberalismo que norteou a sua elaboração.

Por sua vez, cabe ressaltar que mundialmente a elaboração legislativa, para a proteção dos direitos da personalidade somente é verificada após os horrores da II Guerra Mundial, a exemplo da Declaração Universal dos Direitos humanos de 1948.

No caso específico do presente trabalho, voltado para a proteção dos direitos da personalidade, entre eles os direitos relacionados à imagem, a privacidade e intimidade e sua responsabilidade civil, inicialmente, cabe destacar que esses direitos, foram reconhecidos como fundamentais no inc. $\mathrm{X}$ do art. 5 da Constituição Federal.

Diante do novo suporte, cuja importância nuclear veio a estabelecer um regramento disciplinador sobre o direito intimidade e privacidade trouxe, como consequência, a imposição sanções de cunho civil e criminal, o qual no presente caso ficará restrita a responsabilidade civil. Destarte, fica restrito o presente trabalho a abrangência a possibilidade de recomposição do patrimônio lesado na justa medida da agressão sofrida.

\section{DIREITOS DA PERSONALIDADE}

Urge salientar o fato de que o objetivo deste texto é trazer ao lume um dos mais palpitantes temas da atualidade jurídica brasileira, ainda mais, ressaltado com o desenvolvimento de novas tecnologias de captação e disseminação da imagem, da privacidade e da intimidade das pessoas, as quais, de forma rápida e com abrangência global criam um campo fecundo tanto para a aproximação de pessoas ao redor do globo, como também, para as violações a este direito, ensejando, neste campo específico, a devida reparação civil. 
Inicialmente, cabe descrever os principais caracteres dos direitos da personalidade, constituem, entre aqueles inerentes à pessoa, inatos sem os quais a natureza humana não seria plenamente realizada, consagrada na doutrina de Adriano de Cupis.

Existem certos direitos sem os quais a personalidade restaria uma susceptibilidade completamente irrealizada, privada de todo o valor concreto: direitos sem os quais todos os outros direitos subjectivos perderiam todo o interesse para o indivíduo que equivale a dizer que se eles não existissem, a pessoa não existira como tal. São esses os chamados "direitos essenciais", com os quais se identificam precisamente os direitos da personalidade. ${ }^{3}$

Pela importância dos direitos da personalidade, destacam-se o seu aspecto de direito fundamental, disciplinado entre os quais prepondera a proteção da dignidade da pessoa humana, bem como, pela sua previsão no art. $5^{\circ}$ inc. X da Constituição Federal, na inarredável defesa do direito da privacidade, da intimidade e da imagem. Mas, não se pode esquecer o fato de que o direito de imagem passou a receber o grau de autonomia, em recente passagem constitucional e no Código Civil de 2002, ainda, traz em seu âmago inquietações despropositadas, assim descritas por Anderson Schreiber:

Os precursores dos direitos da personalidade não tratavam da imagem como um direito autônomo, mas como mero instrumento de violação a outros direitos da personalidade, como a honra ou a privacidade. É o equivoco em que incorre ainda hoje o Código Civil, ao afirmar, em seu art. 20, que toda pessoa tem direito a proibir o uso e exposição de sua imagem sem lhe atingirem a honra a boa fama ou a respeitabilidade". Ao contrário do que sugere o dispositivo, a tutela do direito à imagem independe da lesão à honra. Quem veicula a imagem alheia, sem autorização, pode até fazê-lo de modo elogioso ou com a intenção de prestigiar o retratado. Nada disso afasta a prerrogativa que cada pessoa detém de impedir a divulgação de sua própria imagem, como manifestação da sua personalidade. ${ }^{3}$

Por serem direitos inatos, os direitos da personalidade "são adquiridos simultaneamente com a personalidade." ${ }^{, 5}$ Devendo serem assistidos desde a concepção,

\footnotetext{
${ }^{3}$ CUPIS, Adriano de. Os direitos da personalidade. Lisboa : livraria morais, 1961, p. 17.

${ }^{4}$ SCHREIBER, Anderson. Direitos da personalidade. São Paulo : Atlas, 2001, p. 101.

5 TEPEDINO, Gustavo. A tutela da personalidade no ordenamento civil-constitucional brasileiro. In:__ Temas de direito Civil. Rio de Janeiro : Renovar, 2001 p. 33.
} 
consoante o art. $2^{\circ}$ do Código Civil. Mas, não é tudo, pois, a tutela concedida ao seu titular deve ser garantida, inclusive, para após a sua morte, por força do art. 20 , parágrafo único ${ }^{6}$, do Código Civil, constituindo-se em sua vitaliciedade.

Os direitos da personalidade, a exemplo dos demais direitos, não possui a prerrogativa de direito absoluto, assim descrito por José Castan Tobeñas:

O caráter absoluto dos direitos da personalidade não significa que sejam direitos ilimitados. Os direitos da personalidade sofrem limites internos (.v.g. o direito de imagem não impede a divulgação da imagem colhida em local público, em evento de interesse jornalístico) e externos, especialmente diante da colidência destes direitos subjetivos com outros direitos da personalidade e com direitos de outra natureza. $^{7}$

Cite-se, como exemplo desta relatividade normativa, o conflito entre princípios, como ocorre, constantemente, com o princípio da liberdade de expressão, que no caso concreto o julgador deverá decidir entre um ou outro que deverá prevalecer no caso concreto, sem que com isso ocorra à revogação do princípio preterido.

Em razão da ausência de qualquer critério que possa avaliar ou mensurar os direitos da personalidade, estes são classificados entre aqueles extrapatrimoniais "tendo em vista a natureza do objeto, não são apreciáveis economicamente. Não é possível estipular preço para as faculdades humanas que são de valor inestimável." ${ }^{8}$ Quanto vale o conceito pessoal? Quanto vale o conceito social de uma pessoa ilibada, proba, honesta? Para as outras coisas há um preço, para essas não.

Aliado a questão da impossibilidade de aferir um valor aos direitos da personalidade, estes direitos são indisponíveis pelo seu titular, assim descritos por Capelo de Sousa:

O consentimento do lesado não ser admissível como causa justificativa da ilicitude de ofensas ao bem da igualdade de dignidade natural e social e à qualidade personalística permanente de igualdade genérica ao tratamento da lei, dada a indisponibilidade destes bens apenas podendo ser relevantes as renúncias ou limitações a

\footnotetext{
${ }^{6}$ Parágrafo único. Em se tratando de morto ou de ausente, são partes legítimas para requerer essa proteção o cônjuge, os ascendentes ou os descendentes.

${ }^{7}$ TOBEÑAS, José Castan. Los derechos de la personalidad. Madrid : Instituto Editorial Reus, 1952, p. 23.

${ }^{8}$ GARCIA, Enéas Costa. Direito geral da personalidade no sistema jurídico brasileiro. São Paulo : Juarez de Oliveira, 2007, p, 43.
} 
manifestações secundárias, parcelares e ocasionais da igualdade perante a lei. $^{9}$

Os direitos da personalidade, por se tratarem de direitos inerentes a pessoa do seu titular, os quais são intransmissíveis, pois "nem o ordenamento jurídico pode consentir que o indivíduo se despoje daqueles direitos que por corresponderem aos bens mais elevados, têm caráter de essencialidade." 10

Neste caso cabe ressaltar o fato de que: mesmo que o seu titular do direito queira se despojar-se dele, assiste ao Poder Público o dever de restabelecê-lo, citando-se o caso mundialmente conhecido do "arremesso de anão", no qual, mesmo diante da flagrante violação da dignidade da pessoa humana, a qual contava com a aquiescência do "trabalhador" o Conselho de Estado Francês determinou a cessação da prática deste "esporte" por afrontar a dignidade do arremessado, assim descrito por Carlos Affonso Pereira de Souza:

Na decisão de 27.10.1995, o Conselho de Estado francês pela primeira vez reconheceu a dignidade da pessoa humana como elemento integrante da "ordem pública" e, consequentemente, declarou ser a prática do lançamento de anão uma atividade que atenta contra a dignidade da pessoa, não podendo, mesmo voluntariamente, ser exercida pela mesma. ${ }^{11}$

Consequentemente na esfera de proteção do titular, os direitos da personalidade, são irrenunciáveis, ou seja, o seu titular não possui a prerrogativa de renúncia ao seu exercício.

No caso francês, acima citado, o anão que era arremessado, defendeu a tese na qual não havia emprego para ele na sua cidade, razão pela qual pretendia a manutenção do “trabalho" por ele desenvolvido.

Ademais, neste sentido são impenhoráveis e inexpropriáveis, em razão de que estão fora do comércio pela sua essência pessoal. Há que se salientar o fato de que, mesmo diante do seu não exercício, não é possível impor-lhes os contornos de imprescritibilidade. A razão é sobejamente conhecida, pois, acompanham o titular em momento anterior ao seu nascimento, bem como, possuem força normativa para salvaguarda, mesmo após, a morte do seu titular.

\footnotetext{
${ }^{9}$ SOUSA, Rabindranath Valentino Aleixo Capelo de. O direito geral de personalidade. Coimbra : Coimbra, 2011, p. 294.

${ }^{10}$ FERRARA, Francesco. Trattato di diritto civile italiano. Roma : Atheneum, 1921. p, 423.

11 SOUZA, Carlos Affonso Pereira de. Direito das Pessoas e dos Bens. Rio de Janeiro: FGV Direito Rio, 2010.
} 
Por oportuno, agora cabe destacar o conceito de imagem, seus caracteres essenciais, sendo o mais destacado o fato de estar presente entre os direitos fundamentais do art. $5^{\circ}$, inciso $\mathrm{X}^{12}$ da Constituição Federal. Por sua vez, o art. 20 do Código Civil ${ }^{13}$, regula o direito de imagem, associando a boa fama ou a respeitabilidade, traços característicos, sendo este último, relacionado à imagem atributo.

Com isso, toda a violação a esse direito de personalidade, deve receber a devida e indispensável reparação de danos, tendo como justificativa que a imagem pessoa possui um valor, assim passou a constituir o patrimônio pessoa do seu titular com as previsões legais acima descritas.

\section{DIREITO DE IMAGEM}

É de longa data a preocupação do homem com a sua imagem, sendo os primeiros relatos extraídos dos escritos históricos do homem de Cro-magnon 30.000 a.C., presentes nas pinturas rupestres em paredes ou no interior de cavernas, assim consideradas por David de Oliveira Festas.

A relação do ser humano com a imagem, enquanto forma de representação do mundo, encontra-se já presente nos primórdios da civilização humana, desde as pinturas rupestres realizadas pelo homem primitivo até, milhares de anos mais tarde, aos antigos sistemas pictográficos de escrita, dos quais ainda se encontram hoje revestidos em alguma língua asiáticas, como a chinesa. ${ }^{14}$

No Egito antigo, em cada descoberta arqueológica, a importância da imagem fica mais evidente, conforme retrata Patrícia de Almeida Torres "os faraós mandavam esculpir

${ }^{12}$ Constituição Federal, 5 de outubro de 1988.

ART. 5 X- são invioláveis a intimidade, a vida privada, a honra e a imagem das pessoas, assegurado o direito a indenização pelo dano material ou moral decorrente de sua violação;

${ }^{13}$ Art. 20. Salvo se autorizadas, ou se necessárias à administração da justiça ou à manutenção da ordem pública, a divulgação de escritos, a transmissão da palavra, ou a publicação, a exposição ou a utilização da imagem de uma pessoa poderão ser proibidas, a seu requerimento e sem prejuízo da indenização que couber, se lhe atingirem a honra, a boa fama ou a respeitabilidade, ou se se destinarem a fins comerciais.

Parágrafo único. Em se tratando de morto ou de ausente, são partes legítimas para requerer essa proteção o cônjuge, os ascendentes ou os descendentes.

14 FESTAS, David de Oliveira. Do conteúdo patrimonial do direito à imagem. Coimbra : Coimbra, 2009. p. 26. 
sarcófagos em ouro e pedras preciosas com a face dos mesmos, a fim de que sua imagem se eternizasse através dos séculos." 15

Assim sendo, é forçoso concluir que não é de hoje o interesse despertado pelo homem com relação à imagem, quando busca preservá-la para posteridade.

Cabe ressaltar a expressão cunhada pelo Cristianismo, consubstanciada de que o homem é a imagem e semelhança de Deus, presente no Genesis $1,26-27^{16}$, representa outro aspecto importante sobre o direito de imagem.

Destarte, ao intérprete e ao estudioso do direito de imagem, assiste o devido cuidado na salvaguarda deste direito fundamental, em razão da extensão e profundidade conceitual do termo, sendo assim Walter Moraes o descreve "dentre todos os direitos da personalidade, não existe outro tão humano, profundo e apaixonante como direito à própria imagem." 17

O conceito de imagem, por sua vez, para Allessandra Helena Neves, deriva "do latim imago, para significar a reprodução artística de pessoa, coisa ou ser que são objeto de culto ou veneração, obtida por diferentes processos em pintura, escultura, desenho, fotografia, televisão etc."

A imagem envolve vários traços característicos, representados por Clara Heinzmann, representados pela pintura, desenho, fotografia, caricatura ou mesmo decorativa, assim descrevendo o direito de imagem.

O direito a imagem envolve os traços característicos da personalidade, como a fisionomia do indivíduo, a representação do aspecto visual da pessoa pela pintura, pela escultura, pelo desenho, pela fotografia, pela configuração caricata ou decorativa. Envolve ainda, a imagem física, a reprodução em manequins e máscaras, por meio televisivos, radiodifusão, revistas e jornais. ${ }^{19}$

\footnotetext{
${ }^{15}$ TORRES Patrícia de Almeida. Direito à própria imagem. São Paulo : LTR, 1998, p.17.

${ }^{16}$ BÍBLIA SAGRADA. Rio de Janeiro : Barsa, 1965, p. 2.

${ }_{17}^{17}$ CHAVES, Antonio. Direito à própria imagem. São Paulo Revista dos Tribunais. v. 451, p. 11.

${ }^{18}$ NEVES, Allessandra Helena. Direito de autor e direito à imagem : à luz da constituição federal e do código civil. Curitiba : Juruá, 2011. p. 153.

${ }_{19}$ HEINZMANN, Clara. O princípio da dignidade da pessoa humana direito de imagem - dano moral. In: Responsabilidade civil em face da violação aos direitos da personalidade : uma pesquisa multidisciplinar. REIS, Clayton (coord.). Curitiba : Juruá, 2011, p. 64.
} 
A imagem é a forma de identificação da pessoa segundo Gilberto Haddad Jabur, que “a partir de seus traços físicos, fisionômicos ou plásticos. Pode ser também considerada através de outras manifestações humanas, como a voz e sinais distintivos.",20

De forma mais abrangente, Arnaldo Siqueira de Lima, oferta ao conceito de imagem aspectos que congregam não só o restrito ao aspecto meramente visual, mas também da personalidade, assim ponderando "o direito à imagem não deve restringir-se ao aspecto visual do indivíduo, mas toda representação da personalidade humana, dentre eles gestos e expressões.",21

Cabe ressaltar o conceito elaborado por Hermano Duval, sobre o direito de imagem, para o qual não pode ficar restrito dentro dos direitos privados do direito da personalidade. Assim, o direito à imagem é um direito natural, equiparável ao da própria vida, que independe da lei "embora esta lei trace limites ou restrições, aqui inconsiderados quanto ao direito à imagem, mas que os tem. Impossível, portanto, asfixiar o direito à imagem no estreito quadro dos Direitos Privados de personalidade." 22

Compõe o adágio popular a expressão "uma imagem vale mais que mil palavras." Com o atual poder de comunicação, ofertado pelas novas tecnologias, a facilidade e a rapidez de propagação da imagem, esse direito deve ser encarado sob um novo olhar na seara da responsabilidade civil.

A vinculação da imagem ao retratado é incontestável, passando a compor o seu patrimônio pessoal e social, neste sentido leciona Zulmar Antônio Fachin "algo que o acompanha na aventura da vida, sendo manifestação de sua própria personalidade, do seu ser, aquilo que ele apresenta na vida social, em todos os momentos onde quer que ele esteja." 23

Deve-se chamar a atenção ao fato de que a proteção contida no inciso $\mathrm{X}$ do artigo $5^{\circ}$, no que se refere à proteção da imagem retrato, por possuir somente os contornos estéticos do retratado é assim conceituada por Luiz Alberto David Araujo:

Quando, no inciso X do art. $5^{\circ}$ da Constituição Federal, há proteção da imagem, esta ele tratando da imagem-retrato. $\mathrm{O}$ restabelecimento da

\footnotetext{
${ }^{20}$ JABUR, Gilberto Haddad. Liberdade de pensamento e direito à vida privada : conflitos entre direitos da personalidade. São Paulo Revista dos tribunais. 2000, p. 267.

${ }^{21}$ LIMA, Arnaldo Siqueira de. O direito à imagem: proteção jurídica e limites de violação. Brasília : Universa, 2003, p. 19.

${ }_{22}$ DUVAL, Hermano. Direito à imagem. São Paulo : Saraiva. 1988, p. 106.

${ }^{23}$ FACHIN, Zulmar Antônio. A proteção jurídica da imagem. São Paulo : Celso Bastos, 1999, p. 50.
} 
situação anterior do bem deve ser imediato e eficaz, devendo o bem voltar ao statu quo ante, com a maior rapidez possível. ${ }^{24}$

Neste sentido de preservação individual da imagem retrato, Luiz Antonio Rizzato Nunes, aponta como aspecto importante à individualização do direito da imagem retrato e seus respectivos componentes. ${ }^{25}$

Os aspectos físicos -mecânicos compreendem a própria compleição física, com seus contornos, seu funcionamento, suas funções; o rosto, o tronco, os membros, os cabelos, a boca, etc., quer possam ser considerados 'normais' e funcionando 'normalmente', quer não. Nesse aspecto está também protegida a voz.

A fotografia é uma imagem, nesse sentido, que somente pode ser tirada com a autorização do fotografado, tanto quanto o som da voz. No elemento estético está o relacionamento à beleza ou normalidade das características e compleição física.

Mas não é só do objeto retratado que se compõe o direito de imagem, este é mais abrangente, e possui outra forma de conceituação presente na imagem atributo, no qual se reúne uma série de informações relacionadas à determinada pessoa ou grupo de pessoas.

É a consequência da vida em sociedade. O homem moderno, quer em seu ambiente familiar, profissional ou mesmo em suas relações de lazer, tem de a ser visto de determinadas forma pela sociedade que o cerca. Muitas pessoas fazem (ou não fazem) questão de serem consideradas relaxadas, meticulosas, organizadas, estudiosas, pontuais ou impontuais. São características que acompanham determinada pessoa em seu conceito social. É importante verificar que tal característica não se confunde com qualquer outro bem correlato à imagem, como à

honra, por exemplo. ${ }^{26}$

E, encontramos a conceituação da imagem atributo, segundo a qual, o que efetivamente importa é o conceito pessoal que a pessoa possui no meio social em que vive, ou, pelo conceito que goza perante as demais pessoas.

Enquanto na imagem retrato impera a forma objetiva, concreta de reprodução de identificação da pessoa, seja ela representada por aspectos físicos, voz, partes do corpo etc.,

\footnotetext{
${ }^{24}$ ARAUJO, Luiz Alberto David. op. cit. p. 74.

${ }^{25}$ NUNES, Luiz Antonio Rizzato. Comentários ao código de defesa do consumidor : direito material. São Paulo : Saraiva, 2000, p. 40.

${ }^{26}$ ARAUJO, Luiz Alberto David. A proteção constitucional da própria imagem. São Paulo : Verbatim, 2013. p.27.
} 
na imagem atributo, o conjunto é outro, passa-se a ter como base o reflexo da pessoa na coletividade, "deixamos de lado, então, os aspectos físicos da pessoa, e ingressamos num campo em que trazemos à tona o direito à imagem, enquanto reflexo da pessoa diretamente no meio social no qual está inserida."27

Tanto a imagem retrato quanto a imagem atributo são bens personalíssimos, classificados por Sergio Cavalieri Filho, a qual se processa por meio de uma multiplicidade de processos, pois compreendem um plexo de características distintivas, pessoais do seu possuidor, como sendo a "pessoa, através da qual projeta-se, identifica-se e individualiza-se no meio social. É o sinal sensível da sua personalidade, destacável do corpo e suscetível de representação através de múltiplos processos". ${ }^{28}$

A singularidade, o aspecto personalíssimo ou o intuito personae, são atributos pessoais indissociáveis da imagem, razão pela qual possuem um valor tangível ou não, os quais representam a essência da autonomia do possuidor a sua espontaneidade.

A particularidade pessoal do direito de imagem é um dos predicados contidos na doutrina de Fernanda Duarte, na qual há que ser destacado que a imagem representa um aspecto mínimo, uma projeção pessoal.

Num plano de conceituação mínima, a imagem apresenta-se, em princípio, com sendo aquilo que nós projetamos ou queremos que seja projetado de nós mesmos, sob o aspecto físico, para o mundo exterior. Porém, não há que se restringir a característica da imagem à feição, abarcando-se aqui elementos de identificação/distinção do sujeito. ${ }^{29}$

É inequívoco que o processo de captação e difusão da imagem, nos últimos anos, tem experimentado vertiginoso avanço tecnológico, o qual reduziu as distâncias entre pessoas facilitando a sua comunicação, bem como, a democratização do acesso a esses dispositivos, trouxe um número cada vez maior de pessoas às redes sociais ou virtuais.

Este benefício social trouxe consigo, a oportunidade de violação da imagem alheia, bem como a sua divulgação, produzindo casos, que se tornaram lamentavelmente rotineiros de exposição íntima, pessoal, causando prejuízos incalculáveis aos lesados, para os quais não restou outra alternativa senão a ultima ratio do suicídio.

\footnotetext{
${ }^{27}$ NEVES, Allessandra Helena. op. cit. p. 157.

${ }^{28}$ CAVALIERI FILHO, Sergio. Programa de responsabilidade civil. São Paulo : Atlas, 2009, p. 104.

${ }^{29}$ DUARTE, Fernanda; VIEIRA, José Ribas; CAMARGO, Maria Lacombe; GOMES, Maria Paulina. (coords.) Os direitos à honra e à imagem pelo Supremo Tribunal Federal : Laboratório de análise jurisprudencial. Rio de Janeiro : Renovar, 2006, p. 147.
} 
De outro lado, importantes conclusões são extraídas a partir desta "vigília cibernética" das imagens e do comportamento, sem que o seu possuidor tenha dela conhecimento.

Aspectos relacionados à tendência de moda, os costumes, o comportamento individual, familiar ou coletivo são explorados ao máximo pelos instrumentos de captação da imagem, para traçar um perfil do observado.

A partir destas informações captadas é possível formar as convicções mercadológicas, consumeristas, de segurança e até mesmo de saúde pública, com o claro objetivo econômico e financeiro.

Como consequência desse incremento das relações envolvendo as imagens, abre-se a possibilidade de postagens, ingressos em sites de compra e relacionamentos, formular uma avaliação sobre o perfil, uma imagem do seu usuário, suas preferências, modelos de vida e consumo, se é solteiro ou casado, se é heterossexual ou homossexual, de qual classe social pertence etc., com o objetivo de explorar esse conteúdo patrimonial da imagem do consumidor para implementar campanhas publicitárias eficientes.

Em mesmo havendo a comercialização ou não da imagem ou dos seus conteúdos implícitos, esta não tem o condão de alterar a substância corporal do retratado, podendo, inclusive, exercer o direito de não mais ser reproduzidos nos moldes contratados, neste sentido Regina Sahm, formula sua doutrina.

A comercialização da imagem não altera a substância do corpo, não afeta a capacidade de sobrevivência cedida, sempre retorna íntegra ao titular diferentemente da cessão da intimidade, que, uma vez revelada, perde em parte sua integridade.

Nem por isso é absoluto o direito à disposição da imagem no sentido de alienação. A qualquer momento, desde que respeitado direito de terceiro, é ressalvado o direito ao arrependimento. ${ }^{30}$

A proteção ao direito de imagem, da intimidade e da privacidade, previstos no inciso $\mathrm{X}$ do art. $5^{\circ}$ da Constituição Federal, não deixa margem para qualquer dúvida quanto à devida e necessária proteção, tanto sob o cunho material e moral, podendo inclusive a sua cumulação, neste sentido Nelson Nery Junior Rosa Maria de Andrade Nery.

Comentando o artigo $5^{\circ}$, inciso $\mathrm{X}$ da $\mathrm{CF}$. $\mathrm{O}$ texto não deixa dúvida quanto à categoria do dano à imagem, distinta do dano material e moral. É possível, portanto, cumular-se dano material, moral e à

${ }^{30}$ SAHM, Regina. Direito à imagem no direito civil contemporâneo : de acordo com o novo código civil, Lei ํㅜ 10.406, de 10-1-2002. São Paulo :a atlas, 2002, p. 38. 
imagem derivados do mesmo fato (v. STJ 37). Como a norma não impõe limitações à indenização por dano moral, nem remete seu regulamento para a lei, nesse caso ela é ilimitada. ${ }^{31}$

No direito brasileiro, prevalece a compreensão abrangente da imagem em todos os seus elementos caracterizadores, desde que sejam reconhecíveis por sua singularidade ou ainda que possam ser entendidos como bens autônomos.

Os políticos, artistas, ou mesmo das celebridades, a imagem humana sempre despertou a curiosidade e interesse, principalmente se relacionadas à vida privada destas pessoas.

Pelo simples fato de exercer a função pública, profissão ou condição social diferenciada, os direitos da personalidade, entre eles, o direito de imagem, não admite sua relativização, por se integrar ao mega princípio estruturante da República Federativa do Brasil previsto na dignidade da pessoa humana.

Desta forma, todo ataque a imagem, seja quem for o seu titular, merece total defesa administrativa e judicial para a sua preservação como direito essencial a vida das pessoas indistintamente.

É evidente, que embutido na exploração da imagem, há um forte apelo econômico e promocional, com o intuito de disseminação da imagem usando todo tipo de mídia e redes sociais, levando determinadas pessoas a se expor de forma indiscriminada.

Cabe ainda ressaltar, conjugando a proteção do direito de imagem e a sua respectiva proteção reparatória assegurada pela responsabilização civil deve ser ampla e irrestrita, além de exemplar, pedagógico a fim de reparar integralmente o dano sofrido, sendo descabido que a reparação seja feita de forma incompleta, pela metade, como assevera Clayton Reis:

$\mathrm{Na}$ seara da responsabilidade civil, como no direito obrigacional, somente a completa satisfação da vítima, como do credor, podem ser considerada como causas extintivas do dever de indenizar ou da obrigação de prestar. Por essa razão que Daniel Pizarro acentuou que 'indenizar pela metade é responsabilizar a vítima pelo resto'. ${ }^{32}$

Desta forma, diante do ataque aos direitos de imagem, assiste a possibilidade ao seu titular de pleitear a reparação do dano, material e moral, sendo, por igual destacar a presença

\footnotetext{
${ }^{31}$ NERY JUNIOR, Nelson; NERY, Rosa Maria de Andrade. Constituição federal comentada e legislação constitucional. São Paulo : Revista dos Tribunais, 2012, p. 220.

${ }^{32}$ REIS, Clayton. A teoria do risco na modernidade - uma antevisão do futuro. In: Responsabilidade civil. LEITE, Eduardo de Oliveira (coord.) Rio de Janeiro : Forense, 2006, p. 78.
} 
dos textos legais que garantem esta proteção, inicialmente citando o art. $5^{\circ}$ inciso $\mathrm{V}^{33}$ da Constituição Federal que assegura a indenização este bem tão precioso ao ser humano consubstanciados no direito de imagem.

\section{DIREITO A INTIMIDADE E A VIDA PRIVADA}

A exemplo do que restou consignado o direito a intimidade e a vida privada representam sua importância dentro dos direitos da personalidade, carecendo, destarte, de proteção singular. Portanto, é concebido como privada a esfera pessoal abrange as relações com o meio social sem que, no entanto, haja vontade ou interesse na divulgação; a esfera privada compreende os dados relativos a situações de maior proximidade emocional ("contextos relacionais específicos"), como as opções sexuais ou a orientação sexual do indivíduo.

Por outro lado, no que concerne ao conceito à intimidade esta se apresenta a esfera do modo de ser de cada pessoa, ao mundo intra-psíquico aliado aos sentimentos identitários próprios (auto-estima, auto-confiança) e à sexualidade. Compreende as esferas confidenciais e do segredo, referentes à intimidade.

Portanto, a vida privada é mais ampla do que a intimidade da pessoa. A vida privada é composta de informações em que somente a pessoa pode escolher se as divulga ou não. Já a intimidade diz respeito ao modo de ser da pessoa, à sua identidade, que pode, muitas vezes, ser confundido com a vida privada. Podemos dizer, assim, que dentro da vida privada ainda há a intimidade da pessoa.

Dentro da temática tratada neste trabalho, cabe ressaltar a estreita conexão existente entre o direito de imagem e a intimidade e a vida privada do titular de tais direitos, neste pensar Francisco Amaral, os Direitos da Personalidade, são "direitos subjetivos que têm por objeto os bens e valores essenciais da pessoa, no seu aspecto físico, moral e intelectual.”

Como consequência, assevera Marcelo Novelino: "A Constituição protege a privacidade (gênero) ao reconhecer como invioláveis a vida privada, a intimidade, a honra e a

\footnotetext{
${ }^{33} \mathrm{~V}$ - é assegurado o direito de resposta, proporcional ao agravo, além da indenização por dano material, moral ou à imagem;
} 
imagem das pessoas (espécies), assegurando o direito à indenização pelo dano material ou moral decorrente de sua violação." ${ }^{34}$

Conjugando as ponderações até aqui exaradas é possível formular um posicionamento no qual a imagem, a vida privada e a intimidade não podem ser objeto de violação e, consequente, divulgação em meios cibernéticos.

A título exemplificativo cabe ressaltar que as informações obtidas, de forma, a priori, ilegais e repassadas ao site "The Intercept Brasil", as quais fazem referencia atuação de autoridades públicas, inexoravelmente constitui e violação a imagem (são pessoas públicas), a intimidade e a vida privada dessas pessoal.

Sem fazer qualquer juízo de valor sobre o conteúdo das mensagens, textos, mensagens de voz, mas o que se verifica no caso divulgado é uma violação a privacidade dos envolvidos.

Como já asseverado alhures, não assiste razão a afirmação de que pessoas públicas devem receber um grau menor de "proteção" a sua imagem, vida privada e intimidade, como a maioria da doutrina propõem. O que está em discussão é o fato de que criminosos obtiveram mensagens e repassaram ao referido "site" que as tornou de conhecimento geral.

\section{RESPONSABILIDADE CIVIL POR VIOLAÇÃO IMAGEM À PRIVACIDADE E A VIDA PRIVADA}

Antes da promulgação da Constituição Federal de 1988, não havia possibilidade jurídica, para pleitear a reparação em face da lesão à moral, por duas razões, sendo a primeira delas a ausência de dispositivo legal servisse de amparo jurídico a este pleito; e, em segundo momento, em razão de que se entendia à época que para a dor humana não havia como mensurar o valor a ser reparado.

Como referido acima, após a Constituição Federal de 1988, tanto a proteção à imagem quanto a moral foram, insofismavelmente, agasalhadas diante da sua relevância.

Sobreleva destacar que o Superior Tribunal de Justiça, ao editar a Súmula 37, segundo a qual "são cumuláveis as indenizações por dano material e dano moral oriundos do mesmo fato."

${ }^{34}$ NOVELINO, Marcelo. Direito Constitucional. São Paulo : Método, 2016, p. 324. 
Por sua vez, o art. $186^{35}$ e $927^{36}$, ambos do Código Civil, asseguram a reparação de danos àquele que teve seu direito lesado.

Neste sentido, cabe salientar, por ser de fundamental importância os enunciados 406 do Conselho da Justiça Federal, "conclui-se que a responsabilidade pela violação ao direito de imagem e seu conteúdo patrimonial encontra-se elencado entre aqueles em que se dispensa a produção de prova."

Sobre a segunda parte do parágrafo único do artigo 927, restou formulado na $\mathrm{V}$ Jornada de Direito Civil, no Conselho da Justiça Federal, o enunciado 446. “Art. 927. A responsabilidade civil prevista na segunda parte do parágrafo único do art. 927 do Código Civil deve levar em consideração não apenas a proteção da vítima e a atividade do ofensor, mas também a prevenção e o interesse da sociedade."

Sobreleva enfatizar o fato de que na VI Jornada de Direito Civil, editou o enunciado 553, o qual corrobora a contido na decisão acima transcrita. "Nas ações de responsabilidade civil por cadastramento indevido nos registros de devedores inadimplentes realizados por instituições financeiras, a responsabilidade civil é objetiva." Sendo que as inscrições, neste sentido, estão a ferir a imagem atributo do titular, ou seja, em seu "bom nome."

Como corolário deste entendimento, cabe destacar a Súmula 403 do Superior Tribunal de Justiça, da qual se extrai que "Independe de prova do prejuízo à indenização pela publicação não autorizada da imagem de pessoa com fins econômicos ou comerciais."

A jurisprudência do Superior Tribunal de Justiça é pacífica, no sentido de não carecer de prova a utilização e divulgação da imagem. Neste sentido, cita-se o julgamento do Recurso Especial 1217422/MG, cujo relator foi o Ministro Ricardo Villas Bôas Cueva, em demanda indenizatória proposta, por reparação de danos morais, no qual um menor teve sua fotografia reproduzida em matéria de campanha eleitoral, sem a sua concordância.

Neste julgamento, restou decidido que não houve a necessidade de comprovação da utilização da imagem do menor, nem tão pouco a demonstração de prejuízo, por se constituir em um dano com característica de in re ipsa.

\footnotetext{
${ }^{35}$ Art. 186. Aquele que, por ação ou omissão voluntária, negligência ou imprudência, violar direito e causar dano a outrem, ainda que exclusivamente moral, comete ato ilícito.

${ }^{36}$ Art. 927. Aquele que, por ato ilícito (arts. 186 e 187), causar dano a outrem, fica obrigado a reparálo.

Parágrafo único. Haverá obrigação de reparar o dano, independentemente de culpa, nos casos especificados em lei, ou quando a atividade normalmente desenvolvida pelo autor do dano implicar, por sua natureza, risco para os direitos de outrem.
} 
Efetivamente, há uma presunção de ocorrência de dano no caso de exposição indevida da imagem, na justa medida em que é um direito personalíssimo, bem como pode acarretar prejuízos à imagem daquele que teve seu direito violado, bem como ao seu patrimônio pessoal, neste sentido faz-se julgar o Recurso Especial 1.217.422/MG, que "O dever de indenizar decorre do próprio uso não autorizado do personalíssimo direito à imagem, não havendo de se cogitar da prova da existência concreta de prejuízo ou dano.”

Como consequência da utilização indevida da imagem assiste o direito a reparação de danos materiais e morais, independentemente da produção de prova da violação. Todavia, o aspecto mais relevante, que o tema vem a suscitar nos últimos tempos, reside no fato de que os valores das condenações, impostas pelo Poder Judiciário, não estão a surtir o efeito punitivo necessário.

Ao compulsar o repertório jurisprudencial, envolvendo demandas de reparação de danos morais pela utilização indevida da imagem, seja ela retrato ou atributo, o Poder Judiciário tem estabelecido valores muito aquém da importância do direito de imagem, bem como não servem de paradigma para evitar que novas lesões sejam perpetradas.

É evidente, que por trás desse tipo de exploração, há um forte apelo econômico e promocional para a disseminação da imagem usando este tipo de mídia, levando determinadas pessoas a se expor de forma indiscriminada.

A imagem e seus fins econômicos e informativos, sendo alvo de utilização constante pelos meios de comunicação, assim destacado por Sidney Cesar Silva Guerra, "o direito à imagem se destaca dos demais pelo fato de a imagem humana estar sendo utilizada largamente em publicidade de produtos, serviços, entidades, e, principalmente, por parte da imprensa." 37

No mesmo sentido Walter Moraes, amplia, um pouco mais a conceituação ao incluir a forma dinâmica da imagem consignada na captação cinematográfica da imagem.

No plano do direito da personalidade a idéia de imagem é entendida, extensamente, como sendo toda sorte de representação de uma pessoa. Inclui, então, assim a figuração artística da pintura, da escultura, do desenho etc., como mecânica da fotografia. Compreendem não apensas essas versões estáticas da pessoa efigiada, como também as

\footnotetext{
${ }^{37}$ GUERRA, Sidney Cesar Silva. A liberdade de imprensa e o direito à imagem. Rio de Janeiro : Renovar, 2004. p. 57.
} 
formas dinâmicas obtidas pela cinematografia, pela televisão e pela representação cênica. ${ }^{38}$

Este é o cerne da questão relacionada à vulnerabilidade da imagem, da intimidade e da privacidade de qualquer manifestação correlata traz consigo relevante importância. É de expressiva importância destacar que o dano moral, possivelmente impensável há duas décadas é perfeitamente aplicável na atualidade.

A imagem captada com violação a intimidade e a vida privada, bem como os seus consectários como, por exemplo, mensagens de voz e de texto podem ser vista e revista constantemente.

O caráter de múltiplas facetas contido no conceito de imagem é tratado da seguinte forma por Maria Cecília Naréssi Munhoz Affornalli.

A imagem interessa ao Direito como sendo toda e qualquer forma de representação da figura humana, não sendo possível limitar e nem enumerar os meios técnicos pelos quais ela se apresenta vez que, com o avanço da tecnologia, a cada momento surgem novas maneiras e mecanismos capazes de exibir a imagem das pessoas. Assim, desde pelos primitivos desenhos na pedra e nas cavernas, feitos na PréHistória, até por meios contemporâneos, como a pintura, a caricatura, a filmagem, a fotografia, o cinema, os computadores, a internet, a televisão, os impressos etc., pode o semblante humanos ser representado, exibindo-se a sua imagem. ${ }^{39}$

Destarte, o uso de nova tecnologia impõe aos direitos da personalidade uma nova roupagem, tornando, por conseguinte um conceito que evolui a todo o momento, destacandose a exploração da imagem em redes sociais, ou mesmo nos "selfies", até bem pouco tem atrás não eram possíveis de serem feitos e disseminados da forma tão célere como é feita nos dias atuais.

Com isso, a informação contida em uma imagem, reitere-se que uma imagem vale mais que mil palavras podem representar prejuízos pessoais incalculáveis. No mesmo sentido, Mônica Neves de Aguiar da Silva Castro destaca a previsão Constitucional do direito de imagem.

\footnotetext{
${ }^{38}$ MORAES, Walter. Direito à própria imagem: in Enciclopédia Saraiva do direito. Limongi de França (coordenador), v. 25. São Paulo : Saraiva, 1977, p. 340.

39 AFFORNALLI, Maria Cecília Naréssi Munhoz. Direito à própria imagem. Curitiba : Juruá, 2012, p. 23.
} 
A Constituição atual, ao protegê-lo nos incisos V, X e XXVIII, "a", do art. $5^{\circ}$, assegura um bem jurídico inerente à personalidade ou, dito de outro modo, à individualidade da pessoa.

O texto constitucional concede grande importância aos direitos reconhecidos no art. $5^{\circ}, \mathrm{X}$ e, portanto, também à imagem.

Nesse sentido, os coloca em um capítulo que os adjetiva como "fundamentais" a revelar a vontade do constituinte de sublinhar e de tornar efetiva essa qualidade primordial. ${ }^{40}$

A proteção ao direito de imagem, da privacidade da intimidade previstos no inciso $\mathrm{X}$ do art. $5^{\circ}$ da Constituição Federal, não deixam margem para qualquer dúvida quanto à devida e necessária proteção, tanto sob o cunho material e moral, podendo inclusive a sua cumulação, neste sentido Nelson Nery Junior Rosa Maria de Andrade Nery.

Comentando o artigo $5^{\circ}$, inciso $\mathrm{X}$ da $\mathrm{CF}$. O texto não deixa dúvida quanto à categoria do dano à imagem, distinta do dano material e moral. É possível, portanto, cumular-se dano material, moral e à imagem derivados do mesmo fato (v. STJ 37). Como a norma não impõe limitações à indenização por dano moral, nem remete seu regulamento para a lei, nesse caso ela é ilimitada. ${ }^{41}$

A vinculação da imagem ao retratado é incontestável, passando a compor o seu patrimônio pessoal e social, neste sentido leciona Zulmar Antônio Fachin "algo que o acompanha na aventura da vida, sendo manifestação de sua própria personalidade, do seu ser, aquilo que ele apresenta na vida social, em todos os momentos onde quer que ele esteja." 42 Sobreleva enfatizar o fato de que a exposição da imagem demonstra muito da essência pessoal do representado.

\section{CONCLUSÕES}

Em razão do acima exposto, em cotejo entre o direito de imagem e a sua crescente vulnerabilidade, inconteste nos últimos dias, é imprescindível que o Poder Judiciário, bem como as plataformas de busca venham a proteger o direito de imagem, a reparando os danos causados aos seus titulares impondo sanções pecuniárias expressivas, as quais sirvam de

\footnotetext{
${ }^{40}$ CASTRO, Mônica Neves Aguiar da Silva. Honra, Imagem, Vida privada e intimidade em colisão com outros direitos. Rio de Janeiro : Renovar, 2002, p. 16.

${ }^{41}$ NERY JUNIOR, Nelson; NERY, Rosa Maria de Andrade. Constituição federal comentada e legislação constitucional. São Paulo : Revista dos Tribunais, 2012, p. 220.

${ }^{42}$ FACHIN, Zulmar Antonio. A proteção jurídica da imagem. São Paulo : Celso Bastos, 1999, p. 50.
} 
exemplo a que novas violações não venham a ocorrer, a estes que venham a retirar imagens indevidamente captadas e que estão sob seu domínio.

No mesmo sentido, cabe destacar que as mensagens divulgadas pelo site "The Intercept Brasil" são violadoras da imagens, da vida privada e da intimidade dos titulares das mensagens que estão sendo reiteradamente divulgadas.

Não assiste razão a uma maior flexibilidade, ou tolerância sobre a divulgação de mensagens de autoridades públicas, pois se isso se tornar possível estar-se-á criando uma área de tolerância não fixada pela legislação, nem tampouco possível de ser concedida.

Por derradeiro, cabe ressaltar que a proteção da imagem, da privacidade e da vida privada dos seus respectivos titulares não pode ficar a mercê de divulgações sensacionalistas, ainda mais quando estar informações foram obtidas de forma criminosa.

Referências:

AFFORNALLI, Maria Cecília Naréssi Munhoz. Direito à própria imagem. Curitiba : Juruá, 2012.

ARAUJO, Luiz Alberto David. A proteção constitucional da própria imagem. São Paulo : Verbatim, 2013.

BÍBLIA SAGRADA. Rio de Janeiro : Barsa, 1965.

CHAVES, Antonio. Direito à própria imagem. São Paulo Revista dos Tribunais. v. 451.

CASTRO, Mônica Neves Aguiar da Silva. Honra, Imagem, Vida privada e intimidade em colisão com outros direitos. Rio de Janeiro : Renovar, 2002.

CAVALIERI FILHO, Sergio. Programa de responsabilidade civil. São Paulo : Atlas, 2009.

CUPIS, Adriano de. Os direitos da personalidade. Lisboa : livraria morais, 1961.

DUARTE, Fernanda; VIEIRA, José Ribas; CAMARGO, Maria Lacombe; GOMES, Maria Paulina. (coords.) Os direitos à honra e à imagem pelo Supremo Tribunal Federal : Laboratório de análise jurisprudencial. Rio de Janeiro : Renovar, 2006.

DUVAL, Hermano. Direito à imagem. São Paulo : Saraiva. 1988.

FACHIN, Zulmar Antônio. A proteção jurídica da imagem. São Paulo : Celso Bastos, 1999.

FERRARA, Francesco. Trattato di diritto civile italiano. Roma : Atheneum, 1921. 
FESTAS, David de Oliveira. Do conteúdo patrimonial do direito à imagem. Coimbra : Coimbra, 2009.

GARCIA, Enéas Costa. Direito geral da personalidade no sistema jurídico brasileiro. São Paulo : Juarez de Oliveira, 2007.

GUERRA, Sidney Cesar Silva. A liberdade de imprensa e o direito à imagem. Rio de Janeiro : Renovar, 2004.

HEINZMANN, Clara. O princípio da dignidade da pessoa humana direito de imagem - dano moral. In: Responsabilidade civil em face da violação aos direitos da personalidade : uma pesquisa multidisciplinar. REIS, Clayton (coord.). Curitiba : Juruá, 2011.

JABUR, Gilberto Haddad. Liberdade de pensamento e direito à vida privada : conflitos entre direitos da personalidade. São Paulo Revista dos tribunais. 2000.

LIMA, Arnaldo Siqueira de. O direito à imagem: proteção jurídica e limites de violação. Brasília : Universa, 2003.

MORAES, Walter. Direito à própria imagem: in Enciclopédia Saraiva do direito. Limongi de França (coordenador), v. 25. São Paulo : Saraiva, 1977.

NERY JUNIOR, Nelson; NERY, Rosa Maria de Andrade. Constituição federal comentada e legislação constitucional. São Paulo : Revista dos Tribunais, 2012.

NEVES, Allessandra Helena. Direito de autor e direito à imagem : à luz da constituição federal e do código civil. Curitiba : Juruá, 2011.

NOVELINO, Marcelo. Direito Constitucional. São Paulo : Método, 2016.

NUNES, Luiz Antonio Rizzato. Comentários ao código de defesa do consumidor : direito material. São Paulo : Saraiva, 2000.

REIS, Clayton. A teoria do risco na modernidade - uma antevisão do futuro. In: Responsabilidade civil. LEITE, Eduardo de Oliveira (coord.) Rio de Janeiro : Forense, 2006.

SAHM, Regina. Direito à imagem no direito civil contemporâneo : de acordo com o novo código civil, Lei no 10.406, de 10-1-2002. São Paulo : Atlas, 2002.

SCHREIBER, Anderson. Direitos da personalidade. São Paulo : Atlas, 2001.

SOUSA, Rabindranath Valentino Aleixo Capelo de. O direito geral de personalidade. Coimbra : Coimbra, 2011.

SOUZA, Carlos Affonso Pereira de. Direito das Pessoas e dos Bens. Rio de Janeiro: FGV Direito Rio, 2010.

TEPEDINO, Gustavo. A tutela da personalidade no ordenamento civil-constitucional brasileiro. In: Temas de direito Civil. Rio de Janeiro : Renovar, 2001. 
TOBEÑAS, José Castan. Los derechos de la personalidad. Madrid : Instituto Editorial Reus, 1952.

TORRES Patrícia de Almeida. Direito à própria imagem. São Paulo : LTR, 1998. 